\title{
No substantial long-term bias in the Cenozoic benthic foraminifera oxygen-isotope record
}

\author{
David Evans (10) ${ }^{1}$, Marcus P.S. Badger (1) ${ }^{2}$, Gavin L. Foster ${ }^{3}$, Michael J. Henehan (1) ${ }^{4}$, Caroline H. Lear (1) ${ }^{5} \&$ \\ James C. Zachos 6
}

The early Cenozoic ( 50 million years ago) was an interval of global warmth that saw cold-blooded reptiles living in the polar regions while mangrove swamps thrived in northern Europe. Foraminiferal oxygen isotope ratios $\left(\delta^{18} \mathrm{O}_{c}\right)$ represent one of several independent proxies used to place quantitative constraints on palaeotemperature during this 'greenhouse' interval. However, the interpretation of geochemical proxy data requires that the possible presence of diagenetic alteration be ruled out or accounted for. To this end, Bernard et al. ${ }^{1}$ conducted laboratory experiments to determine whether solid-state diffusion (SSD) of oxygen between solution and planktonic foraminiferal calcite could impact $\delta^{18} \mathrm{O}_{c}$ of fossil material. Based on a single experiment on recent shells of the planktonic species Globigerina bulloides, maintained for three months at $300{ }^{\circ} \mathrm{C}$ and 200 bars in ${ }^{18} \mathrm{O}$-pure artificial seawater, the authors found that foraminiferal calcite can exhibit elevated ${ }^{18} \mathrm{O} /{ }^{16} \mathrm{O}$ ratios in the absence of any visible recrystallisation. Using this result, Bernard et al. question the integrity of the deep-sea benthic foraminiferal $\delta^{18} \mathrm{O}$ record ${ }^{2}$. Specifically, they suggest that SSD over $\sim 50$ million years could result in a long-term bias of $\sim 1-3 \%$ in benthic foraminifera $\delta^{18} \mathrm{O}_{c}$, such that high-latitude sea surface temperatures (SST) in the regions of deep water formation at $50 \mathrm{Ma}$ were similar to modern. If correct, this would imply that the early Cenozoic greenhouse was not characterised by a reduced latitudinal SST gradient, and moreover, that deep ocean cooling and ice growth over the Cenozoic have been overestimated. We question these findings based, not least, on two fundamental observations.

First, beyond the warmth suggested by the presence of, e.g. cold-blooded reptiles ${ }^{3}$, alternative quantitative Eocene proxy data from the high-latitude surface ocean can be used as an independent means of assessing the benthic foraminifera $\delta^{18} \mathrm{O}$ record, as the temperature of the deep ocean cannot be greatly decoupled from mean annual SST in the region(s) of deep water formation due to the thermal inertia of water. Crucially, most of these independent proxy systems cannot be susceptible to SSD as they are not based on $\delta^{18} \mathrm{O}_{c}$. Figure la shows the Eocene portion of the benthic $\delta^{18} \mathrm{O}$ record interpreted in terms of temperature, assuming that $\delta^{18} \mathrm{O}_{\text {sw }}$ in an ice-free world was $-1 \%$. Proxy SST reconstructions based on the relative abundances of Thaumarchaeotal organic membrane lipid molecules (GDGTs) from ODP Site $1172\left(\sim 58{ }^{\circ} \mathrm{S}\right)^{4}$, clumped isotopes in shallow-dwelling molluscs from Seymour Island $\left(\sim 67^{\circ} \mathrm{S}\right)^{5}$, as well as multiple other lines of evidence ${ }^{6}$, demonstrate that the Eocene was characterised by high-latitude SST greatly exceeding modern (Fig. 1a, b). Furthermore, deep-ocean temperatures based on benthic foraminiferal $\mathrm{Mg} / \mathrm{Ca}$ ratios ${ }^{7}$ are within error of the $\delta^{18} \mathrm{O}_{c}$ record for the ice-free early Eocene (Fig. 1a), which would be highly coincidental if both were diagenetically biased. While all proxies have associated uncertainties, the coherence of trace element, isotopic and organic proxy data, all of which reconstruct high-latitude SST $10-20{ }^{\circ} \mathrm{C}$ warmer than at present throughout the Eocene, are irreconcilable with deep ocean temperatures similar to today, as suggested by Bernard et al. We stress that these independent proxy datasets are globally distributed (Fig. 1b), underwent very different post-depositional histories, and have widely differing susceptibilities to diagenetic alteration. What is more, recent climate modelling work has shown that a reduction in the latitudinal SST gradient of the magnitude shown by the multiple proxies in Fig. 1b is physically plausible ${ }^{8}$.

Second, if solid-state oxygen diffusion has impacted Eocene benthic foraminiferal calcite, a testable hypothesis is that $\delta^{18} \mathrm{O}_{c}$ from different sites within a given time-slice should exhibit large differences that are well-correlated with burial depth or geothermal heating. The most negative benthic $\delta^{18} \mathrm{O}$ values of the Cenozoic are observed between 48 and $54 \mathrm{Ma}$, and since these data span 11 different sites, we use this interval to test Bernard et al.'s hypothesis that these negative values are due to burialinduced SSD. Although the 11 sites span a range in maximum (i.e. present day) burial depth of between $\sim 50$ and $350 \mathrm{~m}$, there is no visible offset between any individual site and the 5-point running mean through all sites (Fig. 1c). This analysis is quantitatively extended in Fig. 1d, e, which display the mean offset of

\footnotetext{
${ }^{1}$ School of Earth \& Environmental Sciences, University of St Andrews, St Andrews KY16 9AL, UK. ${ }^{2}$ School of Environment, Earth and Ecosystem Sciences, The Open University, Milton Keynes MK7 6AA, UK. ${ }^{3}$ Ocean and Earth Science, National Oceanography Centre Southampton, University of Southampton, Southampton SO17 1BJ, UK. ${ }^{4}$ Helmholtz Centre Potsdam, GFZ German Research Centre for Geosciences, Telegrafenberg, 14473 Potsdam, Germany.

${ }^{5}$ School of Earth and Ocean Sciences, Cardiff University, Cardiff CF10 3AT, UK. ${ }^{6}$ Department of Earth and Planetary Sciences, University of California, Santa Cruz 95064 CA, USA. Correspondence and requests for materials should be addressed to D.E. (email: de32@st-andrews.ac.uk)
} 

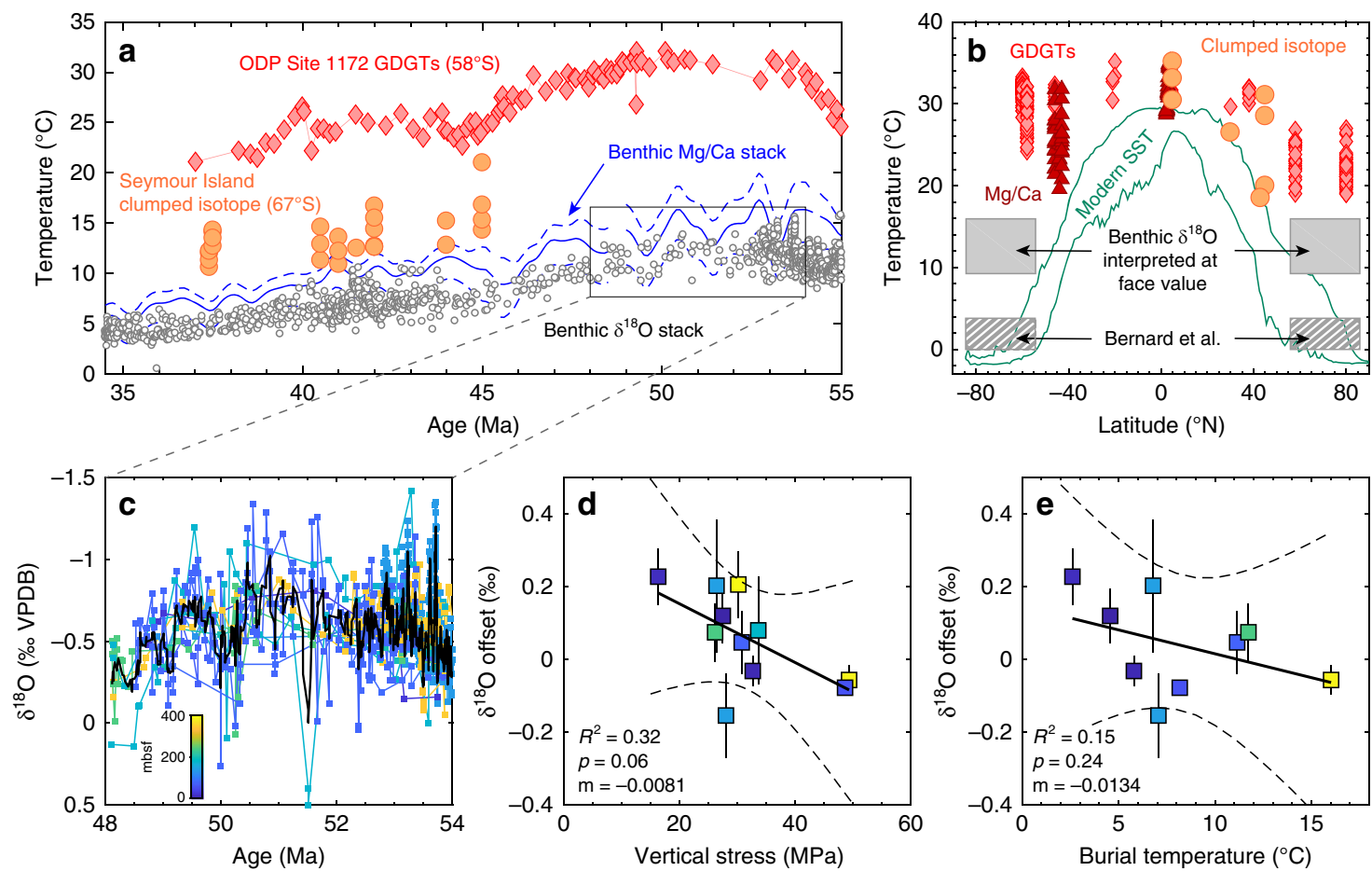

Fig. 1 Multiple lines of evidence for early Eocene high-latitude warmth and integrity of the benthic oxygen isotope stack. a The Eocene benthic $\delta^{18} \mathrm{O}$ record ${ }^{2}$ interpreted in terms of temperature, assuming $\delta^{18} \mathrm{O}_{\mathrm{sw}}=-1 \%$ in an ice-free world. The benthic $\mathrm{Mg} / \mathrm{Ca}$ record ${ }^{7}$ (independent of ice volume) and highlatitude SST proxy data are shown for comparison $5,13-15$. GDGT abundances are transformed into SST using the TEX ${ }_{86}{ }^{\mathrm{H}}$ calibration. $\mathbf{b}$ Early Eocene SST proxy data (48-55 Ma) shown in the context of the zonal range in modern mean annual temperature, demonstrating high-latitude Eocene SST warmth and greatly reduced latitudinal gradient, see ref. ${ }^{6}$ and references therein. Grey boxes show deep ocean temperatures based on benthic foraminiferal $\delta^{18} \mathrm{O}$, both interpreted at face value and following Bernard et al.'s SSD model (which implies 0-1\%o Eocene-Pleistocene change in $\delta^{18} \mathrm{O}_{c}$ due to cooling, i.e. the Eocene deep ocean was $\sim 0-4{ }^{\circ} \mathrm{C}$ warmer than at present). These are plotted as boxes in the high-latitudes as high-latitude SST in the regions of deep water formation cannot be greatly decoupled from the deep ocean. Note that Bernard et al.'s analysis is offset by $>15^{\circ} \mathrm{C}$ from the other high-latitude SST proxy data, in contrast to the benthic record interpreted at face value. c Detail of the benthic $\delta^{18} \mathrm{O}$ record between 48 and $54 \mathrm{Ma}$ (encompassing the long-term warming and cooling trend either side of the Eocene climatic optimum, $50-52 \mathrm{Ma}$ ), with data from different sites coloured as a function of burial depth (metres below sea floor; mbsf). The black line is a 5-point running mean. $\mathbf{d}$ The mean offset of individual sites shown in $\mathbf{b}$ from a 5-point running mean through the remainder, plotted as a function of vertical stress $( \pm 2 \mathrm{SE})$, based on the present-day water depth and depth in sediment, and the mean density of ocean sediment ${ }^{16}$. Statistics and $95 \%$ confidence intervals are based on 1000 bootstrap simulations including 2 SE errors in both variables. The colour scale is the same as in $\mathbf{c}$. Regressing the $\delta^{18} \mathrm{O}$ offset against mbsf results in an even less significant slope. $\mathbf{e}$ The same exercise as in $\mathbf{d}$, except shown as a function of burial temperature. There is no significant relationship between geothermal heating and $\delta^{18} \mathrm{O}$ despite an inter-site range in burial temperature of $14^{\circ} \mathrm{C}$. The slope is an order of magnitude smaller than predicted by Bernard et al.'s SSD model. e Contains fewer datapoints than $\mathbf{d}$ because reliable measurements of the geothermal gradient are not available for all sites

individual sites from a 5-point running mean through the remainder, plotted as a function of present-day total vertical stress and geothermal heating respectively. No individual site is offset from the running mean by more than $0.2 \%$ (equivalent to $<1{ }^{\circ} \mathrm{C}$ temperature bias), despite a range in burial depths of $\sim 300$ $\mathrm{m}$ and $\mathrm{a} \sim 14^{\circ} \mathrm{C}$ range in geothermal heating. This is at odds with the SSD calculations of Bernard et al., which would predict an order of magnitude larger $(>2 \%$ ) range in Eocene inter-site benthic $\delta^{18} \mathrm{O}$, including very little SSD at the shallowest, coolest sites. We note that the deep ocean is not spatially homogeneous with respect to temperature, $\Delta\left[\mathrm{CO}_{3}{ }^{2-}\right], \delta^{18} \mathrm{O}_{\mathrm{sw}}$, or the prevalence of early-stage diagenetic recrystallisation. Therefore, the minor offset between Eocene sites that we observe may reflect primary geochemical signals.

Based on the above considerations, we demonstrate there is little or no evidence for a substantial temperature/burial depthdependent SSD-derived bias in the Cenozoic benthic $\delta^{18} \mathrm{O}$ record, and abundant evidence supporting high-latitude, and therefore deep ocean, warmth. Given that Bernard et al. show that SSD can occur in certain situations, the question then becomes: why are the SSD effects expected on the basis of their experimental results not seen in fossil foraminifera? One potential reason is the calcite grain size the authors assumed when applying their SSD model to foraminifera, such that experimental work on core-top specimens may not be an appropriate basis from which to extrapolate to fossil samples. Bernard et al. use a published foraminifer grain size estimate of $50-250 \mathrm{~nm}$ to derive an activation energy (Ea) of 82-94 $\mathrm{KJ} \mathrm{mol}^{-1}$. Crucially, this ignores the fact that early-stage minor diagenetic recrystallisation of benthic foraminiferal calcite likely results in a larger grain size 9,10 compared to pristine modern specimens. This is a different process to SSD, which cannot significantly alter the bulk isotopic composition of individual shells as early recrystallisation takes place soon after burial and therefore at a similar temperature to the overlying deep water, resulting in calcite with a similar $\delta^{18} \mathrm{O}_{c}$ to the primary foraminiferal calcite ${ }^{11}$. To our knowledge, there are no published estimates of calcite grain sizes in fossil benthic foraminifera, although previous studies have noted a large diagenetic crystal size in planktonic foraminifera on the ocean floor ${ }^{9,10}$. If minor recrystallisation results in an increase in grain size to $500 \mathrm{~nm}$, for example, then the Ea applicable to fossil foraminifera would be $\sim 100 \mathrm{KJ} \mathrm{mol}^{-1}$ and SSD would impact Eocene benthic 
foraminifera $\delta^{18} \mathrm{O}$ by $<1 \%$, in good agreement with our analysis (Fig. 1d, e). A crystal size of $\sim 1 \mu \mathrm{m}$ would mean the applicable Ea is $>120 \mathrm{KJ} \mathrm{mol}^{-1}$, in which case SSD would be unresolvable in Cenozoic samples. Thus, until the grain size and hence susceptibility of fossil foraminifera to undergo SSD has been fully determined (as opposed to pristine modern samples), the results of Bernard et al. cannot inform us of the potential presence of a long-term bias when interpreting $\delta^{18} \mathrm{O}$ data from Cenozoic carbonates.

Despite the disagreement discussed above, we concur with Bernard et al. that a thorough understanding of diagenetic processes is essential to informative palaeoclimate reconstructions. Indeed, it may be that SSD is important in certain situations and should be considered when interpreting sample data from earlier in the Phanerozoic and Proterozoic. However, within the Cenozoic benthic record we show at most a minor effect of burial depth and geothermal heating on $\delta^{18} \mathrm{O}_{c}$ (Fig. 1c-e), which would not be the case if SSD, as parameterised by Bernard et al, were the cause of significant bias. In addition, numerous other proxies corroborate high-latitude (and therefore deep ocean) Eocene warmth, in good agreement with the benthic $\delta^{18} \mathrm{O}$ stack interpreted at face value. Contrary to the assertion of Bernard et al.'s title, reconciling deep-ocean temperatures similar to today with an ice-free, high- $\mathrm{CO}_{2}$ world ${ }^{12}$ would be a greater 'paradox' than the current challenges facing the palaeoclimate community.

Received: 5 March 2018 Accepted: 28 June 2018

Published online: 23 July 2018

\section{References}

1. Bernard, S., Daval, D., Ackerer, P., Pont, S. \& Meibom, A. Burial-induced oxygen-isotope re-equilibration of fossil foraminifera explains ocean paleotemperature paradoxes. Nat. Commun. 8, 1134 (2017).

2. Zachos, J. C., Dickens, G. R. \& Zeebe, R. E. An early Cenozoic perspective on greenhouse warming and carbon-cycle dynamics. Nature 451, 279-283 (2008).

3. Eberle, J. J., Greenwood, D. R. \& Ra, M. Life at the top of the greenhouse Eocene world - a review of the Eocene flora and vertebrate fauna from Canada's High Arctic. Geol. Soc. Am. Bull. 124, 3-23 (2012).

4. Bijl, P. K. et al. Eocene cooling linked to early flow across the Tasmanian Gateway. Proc. Natl Acad. Sci. USA 110, 9645-9650 (2013).

5. Douglas, P. M. J. et al. Pronounced zonal heterogeneity in Eocene southern high-latitude sea surface temperatures. Proc. Natl Acad. Sci. USA 111, 6582-6587 (2014).

6. Evans, D. et al. Eocene greenhouse climate revealed by coupled clumped isotope- $\mathrm{Mg} / \mathrm{Ca}$ thermometry. Proc. Natl Acad. Sci. USA 115, 1174-1179 (2018).

7. Cramer, B. S., Miller, K. G., Barrett, P. J. \& Wright, J. D. Late Cretaceous-Neogene trends in deep ocean temperature and continental ice volume: Reconciling records of benthic foraminiferal geochemistry $\left(\delta^{18} \mathrm{O}\right.$ and $\mathrm{Mg} / \mathrm{Ca}$ ) with sea level history. J. Geophys. Res. 116, 1-23 (2011).

8. Kiehl, J. T. \& Shields, C. A. Sensitivity of the Palaeocene-Eocene Thermal Maximum climate to cloud properties. Philos. Trans. R. Soc. A. 371, 20130093 (2013).

9. Pearson, P. N. et al. Warm tropical sea surface temperatures in the Late Cretaceous and Eocene epochs. Nature 413, 481-487 (2001).

10. Kozdon, R. et al. In situ $\delta^{18} \mathrm{O}$ and $\mathrm{Mg} / \mathrm{Ca}$ analyses of diagenetic and planktic foraminiferal calcite preserved in a deep-sea record of the Paleocene-Eocene thermal maximum. Paleoceanography 28, 1-12 (2013).

11. Edgar, K. M., Anagnostou, E., Pearson, P. N. \& Foster, G. L. Assessing the impact of diagenesis on $\delta^{11} \mathrm{~B}, \delta^{13} \mathrm{C}, \delta^{18} \mathrm{O}, \mathrm{Sr} / \mathrm{Ca}$ and $\mathrm{B} / \mathrm{Ca}$ values in fossil planktic foraminiferal calcite. Geochim. Cosmochim. Acta 166, 189-209 (2015).

12. Anagnostou, E. et al. Changing atmospheric $\mathrm{CO}_{2}$ concentration was the primary driver of early Cenozoic climate. Nature 533, 380-384 (2016).

13. Littler, K., Röhl, U., Westerhold, T. \& Zachos, J. C. A high-resolution benthic stable-isotope record for the South Atlantic: Implications for orbital-scale changes in Late Paleocene - Early Eocene climate and carbon cycling. Earth Planet. Sci. Lett. 401, 18-30 (2014).

14. Cramer, B. S., Toggweiler, J. R., Wright, J. D., Katz, M. E. \& Miller, K. G Ocean overturning since the late Cretaceous: Inferences from a new benthic foraminiferal isotope compilation. Paleoceanography 24, PA4216 (2009).

15. Bijl, P. K. et al. Early Palaeogene temperature evolution of the southwest Pacific Ocean. Nature 461, 776-779 (2009).

16. Tenzer, R. \& Gladkikh, V. Assessment of density variations of marine sediments with ocean and sediment depths. Sci. World J. 2014, 823296 (2014).

\section{Author contributions}

All authors wrote and contributed ideas to this correspondence.

\section{Additional information}

Competing interests: The authors declare no competing interests.

Reprints and permission information is available online at http://npg.nature.com/ reprintsandpermissions/

Publisher's note: Springer Nature remains neutral with regard to jurisdictional claims in published maps and institutional affiliations.

\footnotetext{
Open Access This article is licensed under a Creative Commons Attribution 4.0 International License, which permits use, sharing, adaptation, distribution and reproduction in any medium or format, as long as you give appropriate credit to the original author(s) and the source, provide a link to the Creative Commons license, and indicate if changes were made. The images or other third party material in this article are included in the article's Creative Commons license, unless indicated otherwise in a credit line to the material. If material is not included in the article's Creative Commons license and your intended use is not permitted by statutory regulation or exceeds the permitted use, you will need to obtain permission directly from the copyright holder. To view a copy of this license, visit http://creativecommons.org/ licenses/by/4.0/.
}

(C) The Author(s) 2018 